\title{
Contacts and contracts: cross-level network dynamics in the development of an aircraft material
}

\section{Citation for published version (APA):}

Berends, J. J., Burg, van, J. C., \& Raaij, van, E. M. (2011). Contacts and contracts: cross-level network dynamics in the development of an aircraft material. Organization Science, 22(4), 940-960.

https://doi.org/10.1287/orsc.1100.0578

DOI:

10.1287/orsc. 1100.0578

Document status and date:

Published: 01/01/2011

\section{Document Version:}

Publisher's PDF, also known as Version of Record (includes final page, issue and volume numbers)

\section{Please check the document version of this publication:}

- A submitted manuscript is the version of the article upon submission and before peer-review. There can be important differences between the submitted version and the official published version of record. People interested in the research are advised to contact the author for the final version of the publication, or visit the $\mathrm{DOI}$ to the publisher's website.

- The final author version and the galley proof are versions of the publication after peer review.

- The final published version features the final layout of the paper including the volume, issue and page numbers.

Link to publication

\section{General rights}

Copyright and moral rights for the publications made accessible in the public portal are retained by the authors and/or other copyright owners and it is a condition of accessing publications that users recognise and abide by the legal requirements associated with these rights.

- Users may download and print one copy of any publication from the public portal for the purpose of private study or research.

- You may not further distribute the material or use it for any profit-making activity or commercial gain

- You may freely distribute the URL identifying the publication in the public portal.

If the publication is distributed under the terms of Article $25 \mathrm{fa}$ of the Dutch Copyright Act, indicated by the "Taverne" license above, please follow below link for the End User Agreement:

www.tue.nl/taverne

\section{Take down policy}

If you believe that this document breaches copyright please contact us at:

openaccess@tue.nl

providing details and we will investigate your claim. 


\title{
Contacts and Contracts: Cross-Level Network Dynamics in the Development of an Aircraft Material
}

\author{
Hans Berends, Elco van Burg \\ School of Industrial Engineering, Eindhoven University of Technology, 5600 MB Eindhoven, The Netherlands \\ \{j.j.berends@tue.nl, j.c.v.burg@tue.nl\} \\ Erik M. van Raaij \\ Rotterdam School of Management, Erasmus University, 3062 PA Rotterdam, The Netherlands, \\ eraaij@rsm.nl
}

\begin{abstract}
Tn this paper, we investigate how interorganizational networks and interpersonal networks interact over time. We present a retrospective longitudinal case study of the network system that developed a novel aircraft material and analyze change episodes from a structurationist perspective. We identify five types of episodes in which interpersonal and interorganizational networks interact (persistence, prospecting, consolidation, reconfiguration, and dissolution) and analyze conditions for these episodes and sequences among them. Our findings advance a cross-level perspective on embeddedness and show how individuals may draw on relational and structural embeddedness as distributed resources. The multiple levels of embeddedness impact network dynamics by introducing converging and diverging dialectics, thereby limiting path dependence and proactive network orchestration.
\end{abstract}

Key words: multilevel; network dynamics; product development; structuration

History: Published online in Articles in Advance October 22, 2010.

\section{Introduction}

By entering into interorganizational relationships, organizations can get access to complementary resources (Aiken and Hage 1968, Van de Ven 1976), enabling, for example, complex innovations (Dhanaraj and Parkhe 2006, Powell et al. 1996). The embeddedness in networks also constitutes a resource in itself (Gulati 2007): a firm's existing network position and its past alliances influence subsequent relations, because previous experiences create ties that provide opportunities for future collaboration (Gulati and Gargiulo 1999, Powell et al. 2005, Uzzi 1997). These initial network conditions may be enacted but also adjusted in processes of evaluation, adaptation, and learning (Ariño and de la Torre 1998, Doz 1996, Sydow 2004). The embeddedness of organizations is thus a key factor shaping network dynamics.

The embeddedness of organizations depends on ties at the level of individuals (Barden and Mitchell 2007, Granovetter 1985). Ties at the level of organizations operate through individuals and their connections with counterparts in partner organizations (Seabright et al. 1992), thus creating multiple levels of embeddedness (cf. Dacin et al. 1999, Hagedoorn 2006). However, few empirical studies have investigated the interaction between interorganizational networks and interpersonal networks (Brass et al. 2004, Gulati 2007, Marchington and Vincent 2004). Those studies that looked at the interplay of the two levels have been limited to cross-level effects in existing interorganizational collaborations (Gulati and
Sytch 2008, Seabright et al. 1992, Zaheer et al. 1998) and the role of personal relations in the formation of dyadic interorganizational relations (Barden and Mitchell 2007, Gulati and Westphal 1999, Rosenkopf et al. 2001). In this paper, we aim for more comprehensive understanding of the network dynamics resulting from these multiple levels of embeddedness. Therefore, we investigate how interorganizational and interpersonal networks interact over time, viewing them as distinct phenomena, whereby the latter is not necessarily nested in the former.

We address this question through a retrospective longitudinal case study of the network system that developed and eventually applied a new aircraft material called Glare. Glare is a lightweight sheet material with high fatigue strength and damage tolerance that found its first major commercial application on the Airbus A380 "superjumbo." Development of this material spanned more than 30 years, during which the network system underwent many changes. We adopt a process research approach to investigate the patterns underlying these changes, using qualitative research procedures (Langley 1999, Van de Ven and Poole 1995). Our analysis is informed by structuration theory (Giddens 1984), because its interactive conceptualization of structure and agency reconciles prior research findings on network dynamics and supports the linking of interpersonal and interorganizational networking (Sydow and Windeler 2003). 
The contributions of this paper are as follows. First, to the best of our knowledge, we provide the first process study of networks that includes interorganizational and interpersonal network levels. Second, whereas existing studies have analyzed a single interaction pattern, we identify five different episode types in the recursive structuration of interpersonal and interorganizational networks, and analyze conditions underlying these episodes and sequences among them. Third, we advance theory on multiple levels of embeddedness. Our findings show how the interpersonal level makes embeddedness a distributed resource that may be incongruent across levels and show how this holds for both relational and structural embeddedness. Fourth, we advance process theorizing on network dynamics by showing how the multiple levels of embeddedness result in converging and diverging dialectics that complement evolutionary and teleological explanations of network development.

The rest of this paper proceeds as follows. We first review the literature on the dynamics of interorganizational networks and the embeddedness of organizations in interorganizational and interpersonal networks. After discussing our case study research methods, we present five different episode types in network dynamics and analyze the sequences of episodes found in the case study. Finally, we discuss the implications of these findings for understanding of network embeddedness, describe the limitations of this research, and present our conclusions.

\section{Dynamics in Networks}

\section{Defining Networks}

A network is defined broadly as a set of actors and the set of ties between them representing their relationships (Brass et al. 2004). In this paper, we distinguish between two types of networks: interorganizational networks, in which the actors are organizations, and interpersonal networks, in which the actors are individuals (cf. Oliver and Liebeskind 1998). Interorganizational networks are created by agreements between organizations specifying the contributions, rights, and responsibilities of each organization in the pursuit of a particular objective (Jones et al. 1997, Koza and Lewin 1999). Interpersonal networks consist of individuals tied together within or across organizations through work, advice, and friendship relationships (Brass et al. 2004, Oliver and Liebeskind 1998). The transactional content differs between these types of relations: work relationships exchange goods and services, advice relationships exchange information, and friendship ties exchange affect and social identity (Tichy et al. 1979, Krackhardt 1990). The boundaries of interorganizational and interpersonal networks are defined by the relevance of the relation in facilitating access to resources that may be helpful in the pursuit of a particular objective (Hung 2006, Laumann et al. 1978).
Interorganizational networks and interpersonal networks are separate yet intricately connected and interdependent phenomena (Oliver and Liebeskind 1998). An agreement between two or more organizations to cooperate cannot be enacted without at least work relationships between boundary-spanning individuals (Van de Ven 1976). At the same time, however, many friendship or advice relations may exist between individuals in different organizations without any agreement at the level of the organization (Liebeskind et al. 1996). Thus, although the two networks exist at different levels, the interpersonal network is not necessarily nested within the interorganizational network (Oliver and Liebeskind 1998). Such partial inclusion is a complicating factor to be addressed in cross-level research (Rousseau 1985). We refer to the combination of the interorganizational network and the interpersonal network as the network system.

\section{Dynamics in Interorganizational Networks}

Embeddedness refers to the contextualization of activities in social structures and relations (Dacin et al. 1999, Granovetter 1985). Actions do not occur in a social void but instead are affected by relations resulting from previous actions (Granovetter 1992). Previous experiences provide information about partners, thereby enhancing awareness and understanding of other actors' competencies and resources, and influencing the social attractiveness of other actors by building or destroying trust and commitment (Barden and Mitchell 2007, Granovetter 1985, Gulati 1995b). Mutual understanding, trust, and commitment influence the opportunities and the willingness to engage in collaboration.

Network researchers have distinguished relational and structural components of embeddedness (Granovetter 1992, Gulati 1995b). Relational embeddedness refers to influences of dyadic relationships, whereas structural embeddedness captures the influences of the overall pattern of direct and indirect relations among a set of actors. Structural embeddedness matters when social information originates not only from direct interactions with others but also from indirect connections to third parties (Gulati and Gargiulo 1999).

Longitudinal studies of interorganizational networks have firmly established that the embeddedness of organizations in network relationships affects the subsequent formation of new relationships and future shaping of the network (Uzzi 1997). Two organizations are more likely to engage in an alliance when they have engaged in past alliances together or share common third-party ties (Chung et al. 2000, Gulati 1995b, Gulati and Gargiulo 1999). Consortium members are more likely to remain in a research and development (R\&D) consortium when they have additional ties to other organizations in the consortium (Olk and Young 1997). Furthermore, more centrally positioned organizations will acquire more 
new linkages (Tsai 2000; Powell et al. 1996, 2005), and network structures tend to persist (Walker et al. 1997, Lorenzoni and Lipparini 1999). These tendencies to replicate and strengthen existing relationships and network structures highlight path-dependent consequences of embeddedness, thereby exemplifying evolutionary dynamics (Gulati 1998, Uzzi 1997).

Other process studies of network dynamics have attended more explicitly to agency, allowing for teleological process explanations (Van de Ven and Poole 1995). For example, endogenous network dynamics cannot explain how to access networks without having a prior position in them (Rosenkopf et al. 2001). Indeed, process studies of organizational network dynamics found intentional network design alongside pathdependent network development mechanisms (Doz et al. 2000, Koza and Lewin 1999, Sydow 2004). Firms and individuals may undertake strategic activities to sidestep structures that inhibit network transformation (Capaldo 2007, Rosenkopf et al. 2001), proactively manage relationships through subsequent stages (D'Aunno and Zuckerman 1987, Jap and Anderson 2007), or steer relationship development iteratively, through learning and adaptation to changing conditions (Ariño and de la Torre 1998, Doz 1996, Kumar and Nti 1998, Ring and Van de Ven 1994).

Structuration theory (Giddens 1984) is able to reconcile findings on embeddedness in social structures with process studies of networks that emphasize agency (Gulati 1995b, Li and Berta 2002, Sydow 2004, Sydow and Windeler 1998). Structuration theory provides a dynamic conception of structure and an embedded interpretation of agency, considering them as an interactive duality (Giddens 1984). One of the main concepts of structuration theory, the "duality of structure," asserts that social structures are both the outcome and the very medium of social interaction (Giddens 1976). Agency is embedded in existing structures that both enable and partially constrain human action. At the same time, individuals have the power to "act otherwise," the possibility to say "no" (Giddens 1984). The ongoing construction and reconstruction of structure through embedded agency is called "structuration" and is present in the dynamic interplay of existing relations forming structural conditions for action and actions in turn reshaping those structural conditions (Gulati 1995b, Sydow and Windeler 1998). Whereas the structurationist conception of embedded agency supports the notions of relational and structural embeddedness stressed by evolutionary studies, it also highlights agents' abilities to generate change as stressed by teleological studies.

In addition to evolutionary and teleological mechanisms, structuration theory has been used to highlight dialectical mechanisms in network dynamics (de Rond 2003). Actors engaged in the process of structuration face the "dialectic of control" in that interacting agents are always mutually dependent because relationship partners are always characterized by some degree of autonomy. Actors are influenced by more or less powerful others, but they also have the opportunity to exert control over those others (Giddens 1984, Sydow and Windeler 1998). The dialectic of control has been studied as a phenomenon occurring between organizations (Das and Teng 2000, de Rond 2003, McGuire 1988, Zeitz 1980), emphasizing the engagement of multiple partners in the construction of collaborative structures, each responding to oppositions existing between them. For example, de Rond and Bouchikhi (2004) analyzed the tension between control and autonomy in the relation between alliance partners. Dialectics of control constrain the unilateral construction of social systems and create unpredictability in social dynamics (Sydow and Windeler 1998).

\section{Embeddedness in Interorganizational and Interpersonal Networks}

We seek to extend understanding of interorganizational network dynamics by incorporating the level of interpersonal relations into the analysis. Firms are connected by interpersonal relations at all levels where transactions take place (Granovetter 1985), and these multiple contacts provide potentially different experiences (Barden and Mitchell 2007). Mechanisms of embeddedness may operate both at the interpersonal and interorganizational levels (Barden and Mitchell 2007, Gulati and Sytch 2008). For example, boundary-spanning individuals may trust a partner organization as a whole, or they may trust a specific counterpart in that organization (Zaheer et al. 1998). Relationships among individuals thus play a key role in the embeddedness of organizations. Yet the implications of these multiple levels of embeddedness are only marginally explored, as prior research has mostly focused on a single level (Brass et al. 2004, Klein et al. 2000).

Although longitudinal studies of interorganizational networks have convincingly documented the pathdependent effect of organizations' embeddedness in networks, they do not clarify the role of individuals and interpersonal networks because they usually take the organization or the dyadic relationship between organizations as the smallest unit of analysis (Klein et al. 2000). Research on interpersonal relations, by contrast, has documented the liberal sharing of information in informal networks among professionals from different organizations, based on shared passions and mutual trust, with limited attention for connections with the interorganizational level (Bouty 2000, Brown and Duguid 2001, Dahl and Pedersen 2004, Kreiner and Schultz 1993, Schrader 1991, von Hippel 1987).

A few studies have disentangled interpersonal and interorganizational relations and studied cross-level effects (de Rond 2003, Marchington and Vincent 2004, 
Oliver and Liebeskind 1998). Within existing interorganizational relations, interpersonal experiences have been found to transform into interorganizational trust (Zaheer et al. 1998, Gulati and Sytch 2008), whereas a lack of "chemistry" may subvert interorganizational bonds (de Rond 2003). Moreover, personal ties between senior executives support the creation of formal relations between organizations (Browning et al. 1995, Capaldo 2007, Ring and Van de Ven 1994, Westphal et al. 2006). This has been confirmed in studies focusing on ties originating from previous exchanges among leaders (Barden and Mitchell 2007), executives' previous jobs (Eisenhardt and Schoonhoven 1996, Kim and Higgins 2007), and interlocking directorates (Gulati and Westphal 1999). Research has focused mostly on senior executives, but midlevel managers participating in technical committees (Rosenkopf et al. 2001) and other boundary spanners engaged in interorganizational exchanges have also been found to aid the formation of interorganizational ties (Barden and Mitchell 2007).

Prior research has thus revealed important interpersonal dimensions of organizational embeddedness, evoking calls for more research into the connections between the interpersonal and the interorganizational levels (Brass et al. 2004, Gulati 2007, Marchington and Vincent 2004). We seek to extend the current literature in two ways: first, by studying cross-level interactions over time, not only interpersonal relations as a precursor for organizational ties, and second, by taking a network perspective instead of only a dyadic perspective.

Because structuration theory offers an integrating perspective on prior network dynamics research and addresses the dynamics of individual agency and larger social structures, we use it to guide the investigation of the dynamic consequences of the two levels of embeddedness. We do not deduce specific hypotheses from structuration theory, but we use it as a source of sensitizing concepts, such as the duality of structure, that offer guidance in empirical research for theory development (Blumer 1954, Pozzebon and Pinsonneault 2005). We include both interorganizational networks and interpersonal networks in the analysis as structures that are (re)produced through the practices of organization members. At the same time, individual actions are enabled and constrained by both levels of the network system and by the organizational structure in which individuals are embedded.

\section{Research Methods}

We conducted a retrospective longitudinal case study using qualitative procedures to elaborate theory on embeddedness and network dynamics (cf. Lee 1999, Strauss 1987). Qualitative research procedures were appropriate for the following reasons. First, this study aimed to investigate how changes come about in a complex, multilayered system through evolving interactions of individuals and organizations. This required detailed processual accounts, which can be found in qualitative data sources such as interviews (Langley 1999). Furthermore, an open and iterative approach to data collection and analysis was required because a core objective was to explore and conceptualize these process dynamics (Strauss 1987). Finally, qualitative research allowed the use of multiple, complimentary data sources needed to generate a comprehensive account (Yin 2003).

Our case study focused on the network system around a technological innovation: Glare. Glare is a so-called fiber-metal laminate (FML), a sheet material composed of thin layers of aluminum and an adhesive containing glass fibers. Its recent application on the fuselage of the Airbus A380 marked a highly significant innovation, because the introduction of new classes of materials in the primary structures of aircraft is rare (only wood, metal, and, more recently, composites have been used). We considered this setting well suited to conceptualize cross-level network dynamics (cf. Siggelkow 2007). First, the dynamic system of collaborations extended over a period of about 30 years, in which involvement increased from three core players in the 1970s to more than a dozen organizations in 2008, with organizations entering and retreating from the network at various moments (shown later in Table 2). This allowed a comprehensive investigation of pathdependent network dynamics, including a variety of change episodes (cf. Capaldo 2007). Second, technological innovations often depend strongly on interpersonal networking (Schrader 1991, Oliver and Liebeskind 1998). Indeed, interpersonal relations between members of different organizations surfaced early in our study as a salient characteristic, with some ties going back more than 30 years. The moderate size of the Glare network system allowed us to identify key individuals from all organizations and investigate their relationships. Finally, extensive documentation was available for this case, including historical accounts, patents, publications, and public sources, enabling us to triangulate interviewbased data.

\section{Procedures to Mitigate Retrospective Bias}

We systematically followed key procedures to safeguard from potential retrospective biases (Golden 1992, Huber and Power 1985, Miller et al. 1997, Schwenk 1985): (1) We collected data about each episode from at least three respondents representing at least two organizations, tapping into potential differences in perspectives and emotional involvement, so that biases or lapses were likely to offset those of other informants. (2) We triangulated interview data with other types of data, such as earlier documentation of the case history, coauthorship data, and patents (Jick 1979). (3) Interviews were structured around concrete events, factual data, and actual behavior, which aids the accurate reporting of the past 
(Golden 1992, Miller et al. 1997). Furthermore, interviews were conducted by at least two interviewers, to pick up points missed by one interviewer, and were spread over a period of more than two years, reducing the threat of any single recent event impacting views of the past. (4) The case description was checked with 15 respondents, ensuring that potential differences in interpretation were brought to our attention. Below, we describe our procedures in more detail.

\section{Data Collection}

Data collection started with interviews with central network players (cf. Bell et al. 2006). Our initial sources to identify key informants were a first contact at Stork Fokker (which produces Glare for the Airbus A380) along with the documentation of the Glare history in Vlot (2001). We subsequently applied snowball sampling by asking interviewees for other respondents; following up on stories, organizations, and individuals mentioned in the interviews; and checking with interviewees whether we had identified the most relevant informants. Next, we also identified organizations and interviewees at the periphery of the network, as well as informants who were no longer part of it because of organizational withdrawal, individual retirement, career changes, or conflicts. Thus, we took care to follow up on less successful episodes and broken ties to limit the threat of a bias toward past successes and selfaggrandizement. We interviewed 30 individuals who played a role in the development of Glare. Many of them had served in different organizations over time, so we had, on average, more than three interviewees per organization. The semistructured interviews lasted 90 minutes on average. All interviews, except one, were conducted by at least two members of the research team, recorded, and fully transcribed.

Interviews were prepared in detail on the basis of existing documentation and our understanding of the case history. Interviewees were invited to recount their own professional history and involvement with FML. Then we zoomed in on the specific episodes and relationships the interviewee was familiar with. Finally, based on accounts of other interviewees and our evolving understanding of events, we asked for additional information concerning specific events and relationships. At later moments, 10 follow-up interviews and 7 e-mail conversations were conducted to clarify remaining points of uncertainty.

In addition to interviews, other important sources of data were gathered. We used a number of technical books on Glare and reconstructions of the Glare development, especially Vlot (2001), Vlot and Gunnink (2001), Vermeeren (2002), and Vogelesang (2003). We also collected archival documentation, such as patents, technical publications, graduation theses and dissertations, conference proceedings and participant lists, marketing material on Glare and its predecessor Arall, research program reports and documents, newspaper articles, and public interviews. Patents and scientific publications proved to be a crucial source of additional information on interpersonal relations: coauthorship and coinventorship have frequently been used as indicators of interpersonal collaboration (e.g., Liebeskind et al. 1996, Meyer and Bhattacharya 2004), and acknowledgements in publications contain complementary information (Laudel 2002). The combination of these archival data and interview data provides reliable insight into the existence and characteristics of interpersonal collaborations (Katz and Martin 1997, Laudel 2002). Table 1 summarizes our data sources for different time periods.

\section{Data Analysis}

As a first step in our analysis, we created a comprehensive case narrative, providing a chronological overview of events (Langley 1999). We used QSR NVivo 2.0 to build a case study database and maintain the chain of evidence (Yin 2003), coding interviews for descriptions of actors and periods. We operationalized our definition of the interorganizational network as all legal entities (firms, joint ventures, universities, government institutions) tied to each other through an agreement to codevelop, finance, test, produce, market, or apply FMLs at that point in time. To support the analysis we made diagrams of the changing interorganizational network.

We operationalized the interpersonal network definition as all connections among individuals who were involved in the development of FML with the goal of applying it in the aerospace industry. This interpersonal network included work-related ties (e.g., joint team membership), advice and support relationships (e.g., sharing of information), and friendship ties (e.g., affect and liking). We created diagrams of the interpersonal network at different points in time by analyzing interviews, published case histories, scientific publications and patents, and acknowledgements in papers or dissertations, displaying relationships among about 150 people. Formal evidence for work-related ties was collected from coauthorship of publications and patents. Evidence for an advice and support relationship is, for example, the following acknowledgement in a dissertation: "I am much indebted to Ir. J. W. Gunnink and his colleagues for their research support and provision of materials" (Mueller 1995, p. iii). Furthermore, a friendship tie is, for instance, indicated by the following quote: "I remember that we had an inauguration of the successor of Boud Vogelesang... and he told the auditorium that I was sleeping in the garden house of Jan Willem [Gunnink], which was true... [laughter]."

The case description built from these analyses was sent to 15 interviewees. Their comments resulted in several minor modifications of the case description. We also obtained permission from interviewees to publish the quotes used in this paper. After creating the 
Table 1 Data Sources

\begin{tabular}{|c|c|c|c|c|c|c|}
\hline Periods & Interviewees & $\begin{array}{c}\text { History } \\
\text { descriptions }\end{array}$ & Dissertations & $\begin{array}{c}\text { Relevant academic } \\
\text { publications }\end{array}$ & Patents & Examples of other documents \\
\hline Before 1986 & 15 & 5 & 0 & 6 & 1 & Not available \\
\hline 1986-1990 & 22 & 5 & 2 & 11 & 5 & $\begin{array}{l}\text { TU Delft Arall research project review leaflet; } \\
\text { Akzo leaflet of Arall; Alcoa technical fact } \\
\text { sheet of Arall; Arall conference participant } \\
\text { list }\end{array}$ \\
\hline 1991-1995 & 26 & 5 & 6 & 23 & 3 & $\begin{array}{l}\text { Glare Evaluation Program (SLC) report and } \\
\text { contract; SLC FML leaflets; presentation of } \\
\text { FML study to the Boeing company; } \\
\text { statement of the U.S. Department of } \\
\text { Transportation }\end{array}$ \\
\hline 1996-2000 & 24 & 6 & 6 & 21 & 3 & $\begin{array}{l}\text { Alcoa announcement of cooperation with } \\
\text { Aviation Equipment; GTP reports and } \\
\text { notes }\end{array}$ \\
\hline 2001-2008 & 22 & 4 & 7 & 28 & 30 & $\begin{array}{c}\text { Annual report of NLR; announcements of } \\
\text { Airbus; websites of Airbus, FMLC, TU } \\
\text { Delft, etc.; NIVR presentation on Glare }\end{array}$ \\
\hline
\end{tabular}

narrative and mapping the networks, our second step in the analysis was to identify distinct episodes, as a temporal bracketing analysis strategy, particularly suited to a structurationist approach (Langley 1999, Pozzebon and Pinsonneault 2005). Because our study aims to contribute to theory on interorganizational network dynamics, we define episodes here as changes in the structure of the interorganizational network: the withdrawal of an organization, the (re)involvement of an organization, or a significant change in the formal relationship between two or more organizations. Episodes consist of a series of related events through which structural change unfolds. The 34 episodes so identified were the basic unit of analysis in the remainder of the study (cf. Ariño and de la Torre 1998, Halinen et al. 1999).

For our third analytical step, we analyzed types among the episodes, comparing them to identify similarities and differences (Strauss 1987). Using structuration as a sensitizing concept, we described for each episode the actions involved, the conditions that enabled and constrained those actions, and the network consequences of the episode. Iterative comparison revealed five episode types (persistence, prospecting, consolidation, dissolution, and reconfiguration), representing different ways in which interpersonal and interorganizational networks interacted. These episode types were grounded in data and emerged from our analysis, rather than being predetermined or purely theoretically motivated. During this step, we had to collect additional data for the details of certain episodes and to return to the previous analytical step several times to redefine or split episodes through constant comparison of evidence for the episodes.

Finally, we analyzed chains of episodes for typical sequences over time. Therefore, we coded each episode in terms of the five types and displayed the connections between the episodes in the history of the network. Episode B is considered to be a successor of Episode A if the type (persistence, prospecting, consolidation, dissolution, or reconfiguration) of Episode $\mathrm{A}$ is a condition for the type of Episode B, and Episode B is directly related to Episode A. Differences of opinion were discussed within the research team until consensus was reached. These discussions at various stages of the analysis helped to inhibit tendencies to overidentify with particular interpretations (Pettigrew 1990). We now turn to the findings and start with an introduction to the case history.

\section{Findings}

\section{Case Description}

In 1955, it was established that two crashes of de Havilland Comet jet airliners the year before were attributable to metal fatigue in the aluminum structure, prompting a worldwide search for alternative materials with less fatigue vulnerability and better impact properties. Among those searching for such a material was a network of researchers in The Netherlands. The basis of this network was a long-standing public-private research cooperation between the aircraft manufacturer Fokker, the Dutch aerospace laboratory Nationaal Lucht- en Ruimtevaartlaboratorium (NLR), and the Delft University of Technology (TU Delft). The ties between these organizations were strengthened through employees combining jobs at NLR and TU Delft, or at Fokker and TU Delft. In 1971, researchers at Fokker and TU Delft started studying reinforcements of bonded aluminum structures with fibers, an idea they got from the U.S. aerospace agency National Aeronautics and Space Administration (NASA). However, promising results did not follow quickly, and without the prospect of a commercial application on a new aircraft, Fokker's interest in the material waned. 
In 1978, the research team at TU Delft, led by Boud Vogelesang, had assumed a central role in the network, and their research started to show promising results. This episode is the starting point of our case analysis. In the early 1980 s, more partners became involved through personal contacts of TU Delft's researchers. The North American aluminum producer Alcoa and the Dutch chemical company Akzo each contributed specialist materials expertise on aluminum and on aramid and glass fibers; $3 \mathrm{M}$ contributed adhesives expertise. The industrial partners also helped finance the research and provided materials and lab space, eventually resulting in a new class of aircraft materials based on multiple layers of aluminum and fiber-enhanced adhesives, the so-called FMLs. This type of material shows remarkably smaller and slower crack growth compared with aluminum, thereby enhancing fatigue resistance. Furthermore, the material has higher impact resistance, and if the material is damaged, its residual strength is also higher. The first commercial material was Arall (based on aramid fibers), succeeded by Glare (based on glass fibers).

In 1991, Akzo and Alcoa formed a joint venture, Structural Laminates Company (SLC), to commercialize Arall and Glare and coordinate further research efforts. Several players in the aircraft industry were persuaded to experiment with FML, including MesserschmittBölkow-Blohm (MBB), Aérospatiale, Boeing, and the U.S. Air Force. Commercialization, however, proved very difficult. Because of the high production costs of FML - the process is very labor-intensive - full benefits can only be obtained if the aircraft structure is specifically designed for the use of FML. However, most "new" aircraft are in fact updates of earlier versions, thus severely limiting opportunities for the application of FML. Furthermore, the introduction of any new material for the primary structure of an aircraft requires a long and costly process of testing and certification to ensure safety and meet international regulations.

Because commercial success remained elusive, Alcoa withdrew from the network in 1995, which also meant the end of the joint venture SLC. In the meantime, parts of the now-bankrupt Fokker were taken over by Stork, and in 1998, Stork Fokker became heavily involved as it acquired from Akzo Nobel the license to produce Glare. Researchers from TU Delft convinced Stork Fokker and other network partners to establish the Fiber Metal Laminates Centre of Competence (FMLC) in 2001 to coordinate FML research. Shortly thereafter, a major window of opportunity for the application of the material arose with the announcement of the Airbus A380 "superjumbo," an aircraft that would benefit from lightweight materials because of its large fuselage size. Because Airbus had emerged from a merger of, amongst others, the German MBB and the French Aérospatiale, many researchers with previous FML experience were involved in the development of this new aircraft, which facilitated the choice for Glare. The first A380 flight took place in 2005, some 30 years after initial FML research. The application of Glare on the A380 and Boeing's subsequent decision to develop a fully composite airplane induced Alcoa to reconsider FML. Thus, in 2004, Alcoa reinvigorated FML research activities, in cooperation with former FMLC employees who had founded the company GTM Advanced Structures (GTM), resulting in the material CentrAl in 2007 (FML sandwiched between layers of aluminum). Table 2 provides an overview of the involved organizations.

Our analysis of the episodes discerned in this case history yielded five different types of interaction between the interorganizational ("contracts") and the interpersonal ("contacts") networks: (1) persistence (contacts outlast contracts), (2) prospecting (contacts build contracts), (3) consolidation (contracts build contacts), (4) dissolution (contacts end with contracts), and (5) reconfiguration (contacts change contracts). Figure 1 provides an overview of change episodes and connections among them.

Systematic comparison of the episodes revealed three groups of conditions that help explain the occurrence of a particular type of episode (see Table 3). First, endogenous characteristics of the interorganizational and interpersonal networks, including indirect ties on both levels, affected the occurrence of a particular type of episode. Second, episodes were triggered by perceived opportunities for collaboration, as determined by organizational strategies and personal beliefs. Third, characteristics of individuals' positions - in particular, their autonomy, hierarchical position, and expert powerinfluenced their ability to shape the network system.

For each of the five episode types, we describe one episode in-depth and subsequently discuss the major conditions for this type of interaction. The presentation follows the chronological order of the key examples to facilitate understanding of the whole case study.

\section{Persistence (Contacts Outlast Contracts)}

In persistence episodes, individuals resist network changes at the interorganizational level, reproducing and retaining existing interpersonal relations against the tide of stated organizational intent. The role of individuals in enacting structure is especially evident, as can be seen in the following example of a persistence episode.

1978: Fokker and TU Delft Continue Cooperation Despite Fokker's Reduced Interest. After World War II, Fokker, TU Delft, and NLR formed a close triangle in aircraft development, research, and education, and the Dutch government funded Fokker research projects through its agency for aerospace programs (Nederlands Instituut voor Vliegtuigontwikkeling en Ruimtevaart, or (NIVR)). In 1971, Fokker began studying reinforcements 
Table 2 Involved Organizations

\begin{tabular}{|c|c|c|}
\hline Organization & Period of involvement & $\begin{array}{l}\text { Role in the development of FML and } \\
\text { essential historical information }\end{array}$ \\
\hline TU Delft & 1978- & $\begin{array}{l}\text { Fundamental materials research, research and } \\
\text { development, testing }\end{array}$ \\
\hline Fokker (later Stork Fokker) & $1978-$ & $\begin{array}{l}\text { Development and testing, preparing application on F50, } \\
\text { production of Glare. Fokker went bankrupt in 1996, } \\
\text { and its main parts were sold to Stork }\end{array}$ \\
\hline NLR & 1978- & Testing and certification \\
\hline $3 \mathrm{M}$ & $1981-1995$ & $\begin{array}{l}\text { Supplying adhesive and prepregs, research, and } \\
\text { funding }\end{array}$ \\
\hline Alcoa & $1981-1995 ; 2004-$ & $\begin{array}{l}\text { Funding, supplying aluminum, production of Arall, } \\
\text { marketing, and sales }\end{array}$ \\
\hline Akzo (later Akzo Nobel) & $1981-1999$ & $\begin{array}{l}\text { Funding, supplying fibers, and setting up Glare R\&D } \\
\text { department }\end{array}$ \\
\hline NIVR & 1983- & Government agency funding Dutch R\&D on FML \\
\hline de Havilland (later Boeing, later Bombardier) & 1986-1992; 1996-2005 & $\begin{array}{l}\text { Preparing application on Dash-8; see Bombardier; de } \\
\text { Havilland was subsequently owned by Boeing, by the } \\
\text { Canadian government, and finally by Bombardier }\end{array}$ \\
\hline DFVLR & 1987 & Research and testing \\
\hline MBB (later Airbus) & $1988-$ & $\begin{array}{l}\text { Testing, development, and preparing applications on } \\
\text { several Airbus aircraft; see Airbus }\end{array}$ \\
\hline McDonnell Douglas & $1988-1995$ & Testing and application on C130 (see U.S. Air Force) \\
\hline Boeing & 1991-1995 & Preparing application of Glare on 777 \\
\hline SLC (joint venture Akzo and Alcoa; later SLI) & $1991-1997$ & $\begin{array}{l}\text { Developing, testing, applying, and marketing Glare and } \\
\text { Arall }\end{array}$ \\
\hline Aérospatiale (later Airbus) & $1994-$ & $\begin{array}{l}\text { Glare studies for diverse applications, later especially } \\
\text { for the A380; see Airbus }\end{array}$ \\
\hline Garuda Airlines & 1994-1997 & Glare studies, applications on DC-10 \\
\hline U.S. Air Force & $1995-$ & $\begin{array}{l}\text { Retrofit Glare applications on C130 and studying } \\
\text { applications on other aircraft }\end{array}$ \\
\hline Aviation Equipment & $1995-$ & Production of Glare for several secondary applications \\
\hline Bombardier & $1996-2005$ & $\begin{array}{l}\text { Application on Learjet 45; preparing application on the } \\
\text { C-series aircraft }\end{array}$ \\
\hline Luftwaffe & 1999 & Test application of Glare on A310 aircraft \\
\hline Airbus & $2001-$ & $\begin{array}{l}\text { Since 2001, Airbus has been a fully integrated } \\
\text { company, a merger of, among others, Aérospatiale } \\
\text { and MBB; producing Glare, applying Glare on the } \\
\text { A380, studying applications for the A350 }\end{array}$ \\
\hline FMLC & $2001-$ & Coordinating testing and acquiring funding \\
\hline GTM & $2004-$ & Development and testing \\
\hline Global Technics & $2005-$ & Development and engineering (design) \\
\hline
\end{tabular}

of bonded aluminum structures with fibers, in cooperation with researchers from TU Delft. Initially, however, this research only showed promising results as a local cure for fatigue problems. Furthermore, implementing the concept on a Fokker aircraft could not be realized in the foreseeable future, because Fokker was not developing a new aircraft. Simply replacing the traditional adhesive layers in the structure of an already-certified aircraft with fiber-enhanced adhesive layers would be far too expensive because of certification requirements. As a result, around 1978, FML found itself pitted against other developments deemed more necessary for the future of Fokker. The responsible engineer for material development at Fokker said to Boud Vogelesang, a researcher from TU Delft, "I am the bonding specialist. This development is not worth your money. You'd better stop your research on FML." But Vogelesang replied, "As a researcher, I am free to study what I want. So, I will continue independently and I believe that we will be able to improve this material."

Although Fokker's higher management appeared to be less interested in FML, a number of material and structures developers at Fokker remained convinced of a future for the new material. They maintained their good relationships with TU Delft researchers and continued to cooperate, for example, by performing tests for them. According to Fedde Holwerda, former chief engineer at Fokker, "There were a lot of skeptics... . Then you need these stayers. At a lower level, some people could continue... . People that just persisted and did not follow what's popular, but just continued with the difficult things."

These cooperative research efforts finally resulted in a breakthrough in FML research and in a new material called "Arall" in 1981.

Persistence episodes show that when organizations change or terminate their interorganizational collabo- 
Figure 1 Network Change Episodes

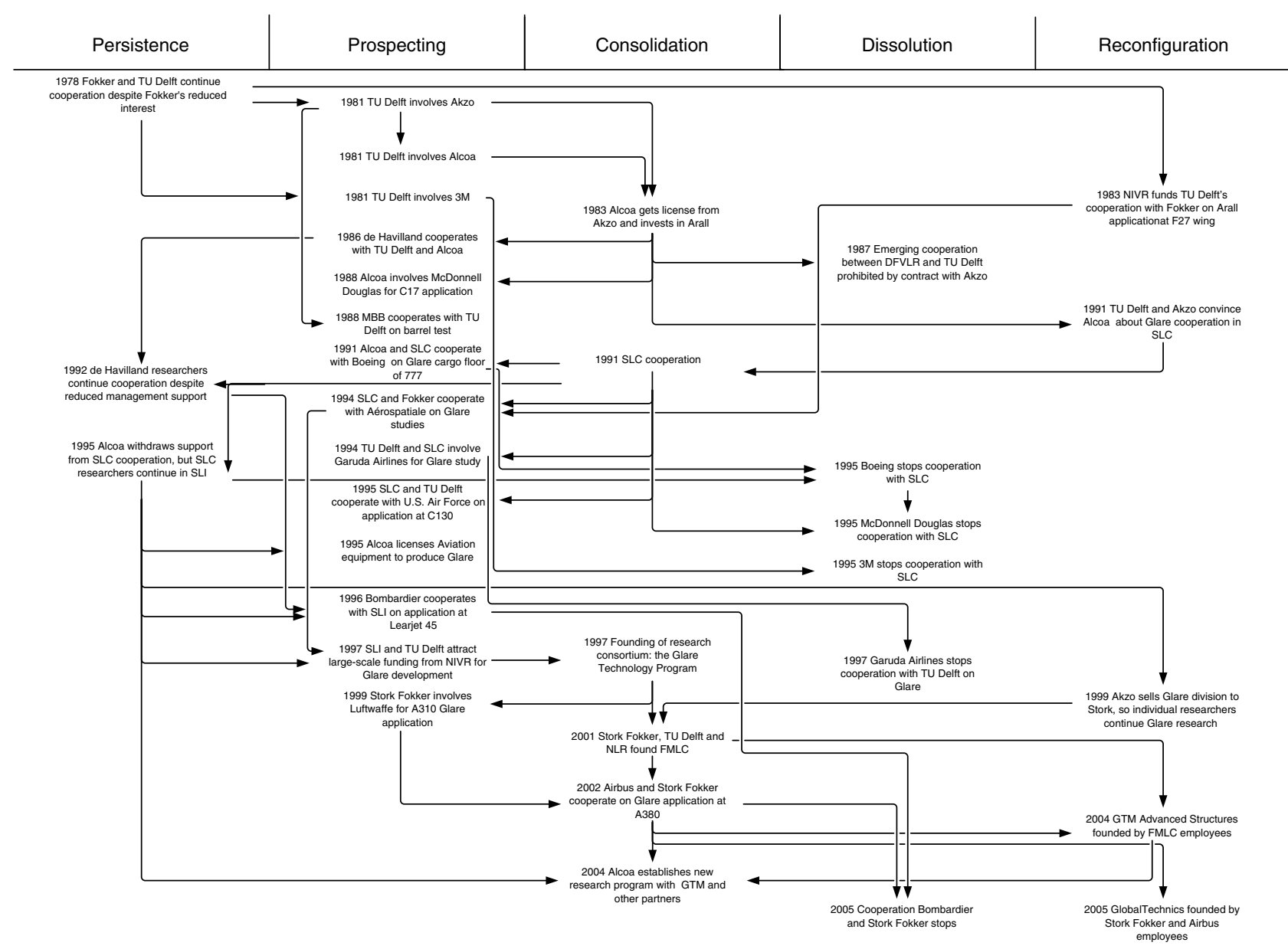

rations, individuals may choose to go along with the new network structure or not. At the interorganizational level, the decision of Fokker's management to withdraw from the direct cooperation with TU Delft was motivated by the strategic conclusion that the research did not create near-term business opportunities (see Table 3). Besides that, other investments enjoyed greater priority, so Fokker's formal withdrawal constrained interorganizational-level cooperation.

At the interpersonal level, work-related ties were cut, but quite often, new advice and friendship ties had been established as a result of the organizational collaboration. Various interviewees have described how a shared passion for advanced materials established bonds between people that proved to be very difficult to break. For example, when in 1992, in another critical episode, de Havilland decided to divest its FML research program, Leo Kok continued to exchange information with researchers from SLC with an eye on opportunities for a new research program:

It became a case of keeping aware of what the competition was doing at the time. But then you didn't necessarily let your management know that you knew what your friends at competitors were doing.... We'd go to the same conferences and have lunch together and talk ideas and things like that. So there were the typical Aeromat conferences. They were the big ones where everybody escaped to California, I guess for structures and new materials and then you know the Alcoa guys were always there. And they were still interested even though they couldn't always fully participate in your programs. That network was more or less intact.

Bill Evancho, former president of SLC, confirmed,

And I still talk to him [Leo Kok] from time to time. The people who have been involved stayed involved. Even though their corporate alliances have changed, their jobs have changed; they still stay in touch and still talk about the technology of fiber metal laminates.

Indirect interpersonal ties stimulated persistence because they increased the informational benefits of direct contacts. For Vogelesang, for example, collaboration with the people at the Fokker research lab also ensured indirect ties to people elsewhere in the Fokker organization. Some years later, these contacts facilitated lobbying chief engineer Holwerda to apply Arall on the new Fokker 50 aircraft. Furthermore, persistence of collaboration in this episode, as well as in other persistence episodes, was enabled by mutual understanding: Fokker 


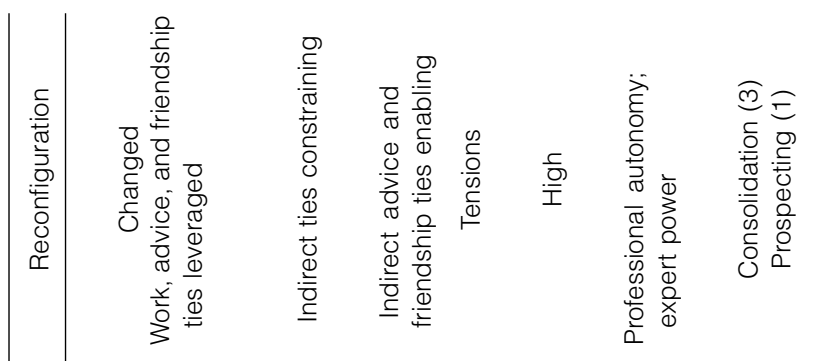

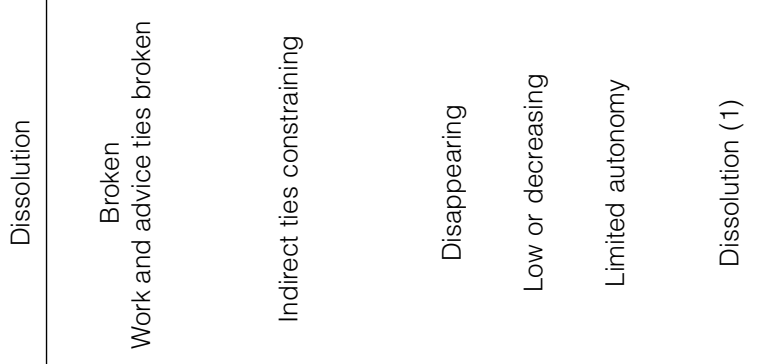

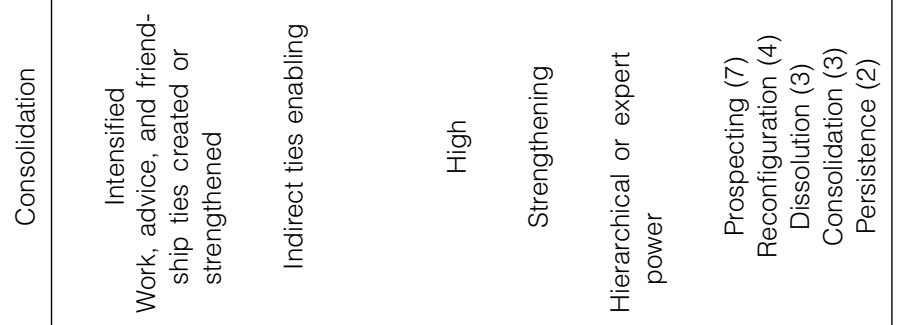

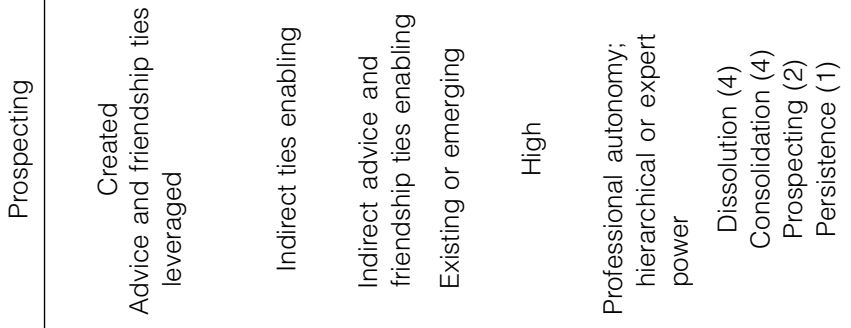

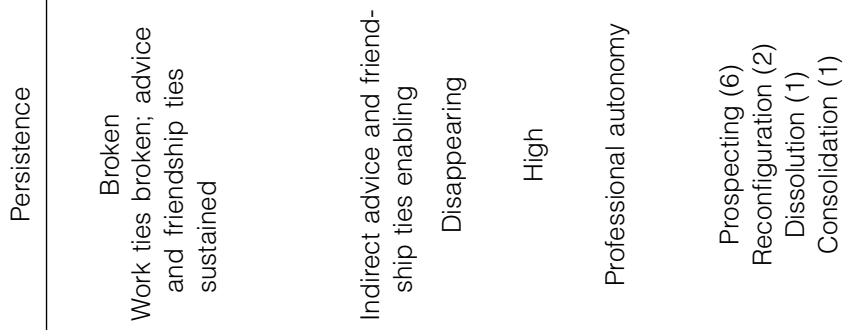


and TU Delft engineers had been working together for a long time on bonding metal. Engineers from both sides shared the belief that the material constituted a revolution toward the construction of lighter and more reliable aircraft:

Once you are infected, you stay infected. When you see that the material has these unique capabilities, then you want to continue with it. You want to be involved... because it creates opportunities you never thought about. (Jan Willem Gunnink, former associate professor, TU Delft)

Moreover, Vogelesang's position as an academic provided him with the much-needed professional autonomy (cf. Oliver and Liebeskind 1998). On the Fokker side, persistence was enabled by the professional autonomy of the developers, supported by the fact that their collaborative work consumed only limited resources and was not highly visible.

\section{Prospecting (Contacts Build Contracts)}

Prospecting episodes are characterized by actors exploring new directions through interpersonal contacts, then formalizing these collaborations at the interorganizational level. In other words, informal contacts lead to formal contracts (cf. Rosenkopf et al. 2001). Prospecting opens up new opportunities for network development. We describe one episode that illustrates prospecting.

1981: Involvement of Alcoa. After Fokker's interest declined, TU Delft became central in FML development. Industrial partners were needed to supply both materials and expertise in fibers, thin aluminum sheets, and adhesives, as well as to gain access to the commercial aircraft market. Searching for an aluminum supplier, TU Delft researchers first explored contacts at the French aluminum producer Pechiney but were not successful. Then, at the Society for the Advancement of Material and Process Engineering conference in Cannes, in January 1981, they met some of their contacts at the American aluminum producer Alcoa. Some initial interest in FML development was generated, and subsequently, letters and samples were sent to Alcoa, but Alcoa's researchers did not pay much attention until one of them developed a personal interest in the material. As Bob Bucci, aircraft materials researcher at Alcoa, told us,

I recall that when I was a student, my Ph.D. advisor, Paul Paris, just kept feeding me these wonderful fatigue and fracture research reports he got from NLR and TU Delft, authored by Jaap Schijve [researcher at NLR and aircraft materials professor at TU Delft]. I felt that Jaap was somebody I had to meet. After joining Alcoa I finally had the pleasure to meet Jaap. It was 1981, at a fatigue conference in Stockholm, and Jaap invited me to visit TU Delft to see some of the interesting work he and his colleagues were doing. I said, "I'd like to do that." When I arrived, one of the things they wanted to show me was some of the early work they had been doing on the development of Arall and Fiber Metal Laminates. They were looking for an aluminum supplier that could supply the thin sheets. After spending a day at Delft with Jaap Schijve, Boud Vogelesang, and Jan Willem Gunnink, I came away convinced and very excited that this was a technology that Alcoa had to be getting into. We were just seeing the first signs of having to compete with composite materials. So, I came back and wrote a rather strong letter to my management and the marketing people.

The Alcoa research community voiced their concern that composites could one day replace aluminum for aircraft, but Bucci was convinced that with Arall, they could both supply their aluminum and play a role in the market for composite materials. Now, his management had to be won over:

It took about two or three years, the discussion within Alcoa about whether we should invest some money to do some research. We formed a little study group, that eventually evolved into a project team. As more and more data was beginning to emerge, we saw the amazing characteristics of these materials. Eventually, we came to a point where our project team started making samples of materials and putting them out to customers.

Alcoa was willing to supply the thin aluminum sheets needed for TU Delft's experimental Arall, although manufacturing these thin sheets was difficult and laborintensive. Somewhat later, Alcoa obtained a license for the commercial production of Arall from Akzo, who owned the patent; for five years, Alcoa had the exclusive rights to produce the material. Alcoa saw market potential, launching the first commercial version of Arall in 1983 and starting production of Arall samples in 1984.

We observe that the formalized cooperation between Alcoa and TU Delft was triggered by shared beliefs in the possibilities of FML arising from informal information sharing in advice relationships. For Bucci, the relationship with TU Delft was enabled by his indirect relation with Jaap Schijve, brokered by his Ph.D. supervisor Paul Paris:

These two individuals were basically giants in the field. So, they had a technical-professional kind of relationship through conferences-sharing interest in a similar discipline.

One key condition for organizations to follow through on the prospecting at the interpersonal level was demonstration of fit between identified opportunities and organizational strategy. But convincing organizations to turn personal ideas into a corporate research and development agenda required a lot of persuasive power and stamina. It took Bucci and his colleagues two years to get Alcoa management to embrace FML as a new development that could strategically defend Alcoa market share against the threat of composite materials.

The progress of prospecting is influenced by the position of individuals in their organizations. Bucci's position gave him professional autonomy to explore new 
directions and bring them to the attention of development managers (cf. Burgelman and Grove 1996). Similarly, engineers from MBB were free to experiment with new materials, and contacts with TU Delft researchers stimulated them to start testing Glare in 1988. Only years later, however, when they had ascended the hierarchical ladder within Airbus, could researchers influence the eventual choice of Glare for the A380. As such, personal relationships between senior managers and executives are more easily turned into formal ties (cf. Westphal et al. 2006). For example, the establishment of the Glare Technology Program was largely enabled by the expert status of Daan Krook, a former director at Airbus and Fokker, who had good relationships with other directors, chief executive officers (CEOs), and government officials.

Several of the prospecting episodes were positively influenced by the partner's indirect interpersonal and interorganizational relationships with other network partners. For Alcoa, the commitment of Akzo to the developments at TU Delft was a condition. Akzo's patent position, backed with experience in fiber production, supported further exploration of the business opportunity. Similarly, relations of Alcoa people with others in the aircraft industry were an additional reason for Vogelesang and others at Delft to pursue a tie with Alcoa. As Bucci stated,

Another reason that Delft was interested in us at that time was our position in the aerospace market. So, through our exposure and contacts we could make these ideas available to our customers.

\section{Consolidation (Contracts Build Contacts)}

The defining characteristic of consolidation episodes is that formal agreements at the level of the interorganizational network result in new interpersonal ties. To a certain extent, this episode type is a mirror of prospecting episodes; whereas the interpersonal network is leading in prospecting, consolidation is triggered by action in the interorganizational network. In the following episode we see how new interpersonal ties are created as a result of an organizational decision to cooperate.

1991: SLC Cooperation. When Alcoa realized its first commercial Arall application in 1988, the relationship between Alcoa and Akzo began to deteriorate. The exclusive production rights for Arall, which Akzo had licensed to Alcoa, were expiring. Furthermore, Akzo was starting its own Glare business, having acquired a new patent from TU Delft. Alcoa's preference to focus on the older Arall created considerable tension between the partners. In the end, Alcoa decided to go along with Akzo and to accept Glare as a second FML product. This resulted in a joint venture, SLC, in 1991, which owned the patents for both Arall and Glare. Because of the earlier disagreements between Akzo and Alcoa, the contacts between Alcoa and the Dutch partners Akzo and TU Delft had soured, but with the formation of SLC, the group was brought back together, and a new shared spirit could emerge. As Bill Evancho, former Alcoa employee and president of SLC, recalled,

Structural Laminates Company consisted of the merger of the Alcoa group that was focusing on Arall and a group that Akzo had formed to promote Glare. Anyway, we had several meetings to form the group.... The company itself consisted of a group of people from The Netherlands, Akzo's people, and a group of Alcoa's people here in the U.S. That group, I believe, functioned together as a single body extremely well. It was a highpowered group. Most of the people got along with everybody else. The few who did not ended up to be transferred out, because we couldn't jeopardize the success of our project.

SLC employed some of those who had been involved in FML development from the very beginning, and they defined the course of the research in close cooperation with the reconnected Alcoa people. From Alcoa's side, the focus was on commercialization and marketing. Subsequently, SLC also allocated research, development, and production tasks to other network partners, like TU Delft, NLR, and Fokker (which had become more involved again in 1983). Moreover, SLC was able to build new relationships, for instance, with Aérospatiale, Boeing, and Bombardier, and to strengthen existing relationships through increased collaboration. Evancho stated,

These people formed close relationships with technologists at the customer locations. They became a very close community.

SLC gave the network a nucleus that performed a pivotal role in coordinating both fundamental materials research and the commercialization of FML.

At the interorganizational network level, one important condition for consolidation was the fit between the contract and a given firm's strategic intent to cooperate with the other parties to exploit complementary resources, increase cooperation, or create protection against opportunism (see Table 3). After Akzo and Alcoa agreed on their joint venture in 1991, cooperation intensified through more frequent interactions and new relationships among persons from both sides, as evidenced by a range of coauthored papers (e.g., Gregory and Roebroeks 1991, Wu et al. 1994). Other episodes of this type show the same pattern: multiple direct and indirect relationships at the interorganizational network level are aligned by a new agreement, which in turn supports increasing growth and density in the interpersonal network. New relationships grow from work to advice relations, and they sometimes evolve into friendships. For example, Rob Fredell, who suspended his work as an engineer for the U.S. Air Force to complete a Ph.D. at TU Delft, acknowledged,

My work was aided in large part by the financial and technical support of Structural Laminates Company. I also consider every member of the SLC team a good friend. Jan Willem Gunnink, Buwe van Wimersma, 
Tom Matway, Rob van Oost, Geert Roebroeks, Arthur Mattousch, Rob Leonard, and Grace Boschman are the people who kept me in laminates and added a real-world influence so important to good research.

(Fredell 1994, p. iii)

In each instance of consolidation, a formal organization-level agreement provided the structure around which interpersonal links could be enhanced and extended (cf. Dahl and Pedersen 2004).

At the interpersonal network level, one key condition was the strong commitment of individuals with higher management positions - such as that of Evancho, Gunnink, and Vogelesang-to make the cooperation agreement work. Furthermore, shared beliefs in FML opportunities were essential to enact the organizational link. Within the SLC team, Evancho used a large kickoff meeting and follow-up events to stimulate interpersonal relationships as well as a shared sense for the importance of the new material. Employees who did not fit his bill of cooperative behavior were replaced, indicating the importance of interpersonal relationships and beliefs. The cooperative behavior of individuals was embedded within the contracts, resulting in mutual reinforcement of the ties at both organizational and individual levels.

\section{Dissolution (Contacts End with Contracts)}

Dissolution episodes are those where the severance of ties at the level of the interorganizational network coincides with the severance of ties in the interpersonal network. In one case, dissolution was triggered by a broken interpersonal tie. Most cases of dissolution were triggered by broken interorganizational agreements, making these episodes the antithesis of persistence episodes, in which interpersonal relationships persist despite the breaking up of ties at the level of the interorganizational network. We describe one illustrative dissolution episode.

1995: 3M Stops Cooperation with SLC. 3M had been part of the network since the early developments of the first FML: Arall. 3M had supplied the adhesive film that contained aramid fibers as a strengthener. This so-called "prepreg" was manufactured in the United States and supplied in small quantities to TU Delft for manufacturing and testing FML. Regular visits by $3 \mathrm{M}$ engineers and managers from St. Paul to Delft were arranged via the 3M Aerospace sales and marketing manager Benelux, Ton Tauber. Although there was no direct income associated with these supplies, $3 \mathrm{M}$ was committed to the development of FML from 1981 to 1995, participating in the shift from aramid fibers to glass fibers. According to Ton Tauber, Boud Vogelesang's enthusiasm for FML was a key reason for 3M's continued interest. In 1995, however, 3M reconsidered its priorities and decided against further investments in prepregs for FML. Over the years, competitors had developed adhesive films with similar properties, and CYTEC became the new prepregs supplier. The $3 \mathrm{M}$ engineers were highly committed to the FML development at the time but had no personal relationships to maintain, as many of them soon retired or simply did not have personal contacts with TU Delft. Some minimal contact was retained, but it did not affect the business project. As Ton Tauber recalled,

The Aerospace management in the U.S. decided at that time to support two in-house $3 \mathrm{M}$ projects and to drop the Glare project... . In the years since $1995 \ldots$. the bond with TU Delft has weakened. I continued to visit Boud [Vogelesang]. I have been at his farewell ceremony, but I was no longer really involved in Arall and Glare.

The sales and marketing manager of $3 \mathrm{M}$ kept paying the occasional visit to TU Delft up to his retirement but felt no longer part of the network developing FML. When large-scale Glare production started in 2002, 3M had already sold its prepreg business and facilities to CYTEC, and there was no opportunity to profitably reenter this market.

The comparison of episodes showed a number of conditions that can lead to relationship dissolution. One condition is that one or more network partners at the organizational level no longer see attractive opportunities stemming from the interorganizational collaboration. At the same time, the bonds at the personal level are not sufficiently strong to maintain cooperation despite the formal decision to break up (cf. Seabright et al. 1992). Advice or friendship ties were often severed as well when the work relationship ended. In the episode described above, and in the breakups between Boeing and SLC in 1995 and between McDonnell Douglas and SLC in 1995, dissolution can be explained by strategic reorientations at the organizational level combined with relatively weak interpersonal bonds.

In the $3 \mathrm{M}$ episode, decision making was largely topdown from the United States, which meant that those with interpersonal ties to the network had little autonomy. Moreover, committed 3M engineers from the early years soon retired: this is a risk when formal cooperation relies solely on a small number of contacts. If key individuals move jobs so that interpersonal ties can no longer be maintained, the organizational tie may break as well. This same dynamic led to dissolution of the tie between Garuda Airlines and SLC when a former Ph.D. student from TU Delft first introduced Glare cargo floors on Garuda aircraft but left for another job within Garuda, and the cooperation ended.

But even when interpersonal bonds are strong, tie dissolution at both levels may still occur. This happened in cases of a formal ban on further exchanges with the former partner. Such organizational bans were intended to sequester knowledge and to ensure exclusive access to resources. They could originate from one of the members of the dyad or from a network partner demanding that ties be severed. For example, Akzo's agreement with TU Delft in the early years to protect FML knowledge severedties at both the interorganizational and interpersonal levels between the German Aerospace Center 
Deutsche Forschungs- und Versuchsanstalt für Luft- und Raumfahrt (DFVLR) and TU Delft. Similarly, Airbus demanded exclusive access to FML, cutting off competing firms' access, and relationships dissolved between Bombardier and Stork Fokker.

\section{Reconfiguration (Contacts Change Contracts)}

In reconfiguration episodes, individuals draw on multiple interpersonal linkages to change existing interorganizational collaborations and to establish new links. Individuals use their agency not to gradually enlarge the network, as in prospecting, or reproduce individual ties, as in persistence, but to rearrange the structure of the interorganizational network. Such individual actors may draw on both interpersonal networks (in particular, ties that are not nested within the network of formal collaboration partners) and their knowledge of organizational preferences (or their ability to affect such preferences). An illustration of this is the founding of GTM Advanced Structures.

2004: GTM Advanced Structures Founded by FMLC Employees. After Alcoa's de facto withdrawal in 1995, SLC's activities were stopped. To continue the coordination of FML research, researchers from TU Delft finally convinced Stork Fokker and NLR to establish FMLC in 2001. One of FMLC's goals was to explore further applications of Glare by disseminating knowledge of Glare to potential users and interested researchers all over the world. Once Glare was adopted by Airbus for the A380, FMLC's industrial partners no longer applauded this idea of wide dispersion of Glare knowledge; Airbus in particular wanted to retain their competitive advantage by keeping knowledge proprietary, and Stork Fokker agreed to supply Glare exclusively to Airbus. As a result, people at FMLC felt hampered in their ambitions because they believed that for a wide acceptance of the material, more companies should be involved in research and experimentation. At the end of 2004, Gunnink, the president of FMLC and an expert on FML design, left to start a new company, GTM Advanced Structures, and the majority of FMLC employees joined this new company. This move was enabled by Gunnink's enduring personal relationships with people at organizations that were formally excluded, including Bucci at Alcoa, Fredell at the U.S. Air Force, and the former Airbus A380 program director Jens Hinrichsen, who had moved to Alcoa. Because of its independent position, GTM could again set up collaborative relationships with influential partners, including Alcoa. In Bucci's words, they "reinitiated the contacts with former friends." Thus, GTM's independence ensured that research on Glare and other FMLs could continue with fewer constraints, and that knowledge of FML could be dispersed more widely. In 2007, the cooperation between GTM, TU Delft, the U.S. Air Force, and Alcoa resulted in the launch of a new FML product, named CentrAl (see, for example, Fredell et al. 2007). Boeing is mentioned as one of the compa- nies interested in CentrAl. Thus, the founding of GTM resulted in network extensions, whereas other network players did not aim for such an extension and indeed resisted it. The network system changed markedly with the establishment of GTM, because Airbus and Stork Fokker no longer controlled the membership and direction of the FML network system.

Reconfiguration episodes show that individuals are only partially constrained by existing social structures and that they may choose to enact a different structure, despite organizational efforts to control their behavior. A number of conditions can be identified for reconfiguration episodes.

Reconfiguration episodes are triggered when organizations and individuals have conflicting views of strategic opportunities (cf. Burgelman and Grove 1996). They develop competing strategic directions, although formalized contracts are needed to exploit the complementary resources for such opportunities. Individuals use their personal contacts to pursue opportunities not in line with management decisions, thus bending things to their will and in the direction they consider to be right.

At the interorganizational network level, structural properties of the network constrained reconfiguration, as the existing contract between Stork Fokker and Airbus constrained cooperation with other network parties. For example, possibilities for FMLC employees were limited through Stork Fokker's influence on FMLC. As such, these contractual obligations constituted structural rigidities (cf. Leonard-Barton 1992). The reconfiguration episodes show that rearrangement could occur despite such rigidities. In all of these cases, individual agency appeared as the initiating spark.

At the interpersonal network level, actions of individuals were enabled by their advice and friendship ties with individuals outside of the network of formal partners. Building on shared beliefs and passions, such ties brokered the reconfiguration at the organizational level. In another reconfiguration episode, Vogelesang's interpersonal relationships with people at both Akzo and Alcoa helped to bring both firms into a new agreement in 1991. To achieve this, Vogelesang wrote to Evancho at Alcoa (Vlot 2001, p. 96):

It was for us very painful to hear from you that some people at Alcoa are feeling themselves betrayed by us. From the bottom of my heart I tell you that they have no reason at all to think like that... . But one thing is essential for us, there needs to be a full understanding and confidence between both our groups.

The utilization of these interpersonal contacts was further enabled by the professional autonomy and the expert power of individuals. For example, the sale of Akzo Nobel's Glare division to Stork in 1999 was brokered by the contacts of former Fokker and Airbus executive Daan Krook with government representatives, and it was enabled by interpersonal links between Akzo Nobel's higher management and that of Stork. In a 1991 
reconfiguration episode, the inventors of Arall could use their expert status and high degree of autonomy as university researchers to promote Glare instead of Arall. Many potential aerospace customers were eager to accept this newer material because the inventors of the earlier material themselves backed it. Consequently, Alcoa had to make the best of a bad bargain and went along with this new direction in FML development.

\section{Episode Sequences}

To shed more light on the dynamic evolution of the network, we analyzed sequences of episodes. Whereas individual episodes show relatively short-term network dynamics, the analysis of episode sequences highlights longer-term network dynamics. These longer-term dynamics exemplify the duality of structure because actions in earlier episodes create conditions for future episodes. The counts of successions among types of episodes, displayed in Table 3, show a broad array of possible connections. Each episode alters interpersonal or interorganizational relations, and these relations may figure as direct or indirect ties in subsequent episodes. The potential direct and indirect effects of ties at both levels imply that multiple and variegated episodes can branch out of any singular episode. This explains the rather messy nature of network development, as portrayed in Figure 1. Yet some successions occurred more frequently than others. Figure 2 highlights four prevailing sequences in the network's dynamics based on successions that occurred at least twice. Each of these prevailing sequences can be explained by the constellation of conditions that are the outcome of one episode and form antecedents for a subsequent episode, in combination with exogenous changes.

The first (1) prevailing sequence is a cycle among prospecting and consolidation episodes. In such successions, interpersonal and interorganizational networks expanded and mutually reinforced each other. Consolidation solidified the interpersonal and interorganizational ties created through prospecting, building on the interorganizational strategy and opportunity fit that emerged from prospecting. In addition, this succession was catalyzed by individuals with hierarchical or expert power effectuating the consolidation. Subsequently, networkwide interorganizational commitment and alignment with

Figure 2 Prevailing Sequence Among Episodes

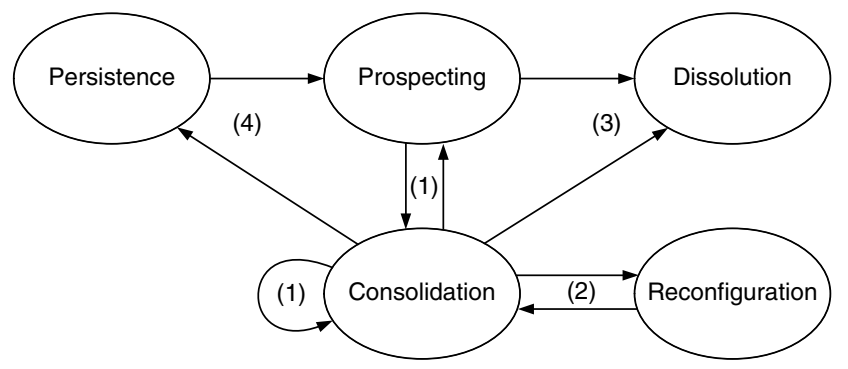

the interpersonal network were leveraged to form new interpersonal ties, thus subsequently enabling further prospecting.

At the interpersonal level, the strengthening of interpersonal ties and the development of shared beliefs about FML were mutually reinforcing in these sequences. Evancho stated,

I think it was a community because they were all technicians initially. Over a period of time, they all got to know each other and formed very good friendships.

Technologists shared evaluation criteria to assess materials for potential application in aircraft (e.g., damage tolerance, fatigue properties, weight). For many of them, professional prestige and career prospects depended on FML success. Frequent interactions strengthened relationships and resulted in a shared understanding and a commitment to the development and application of FML, even characterized by some as "a passion." This, in turn, increased the tendency to cooperate and enhanced the pursuit of formal and organizationally consolidated collaboration.

A second (2) prevailing sequence in network development is formed by successions of consolidation and reconfiguration. The reinforcement of interpersonal and interorganizational relations through successions of prospecting and consolidation was interrupted in successions of consolidation and reconfiguration, which emerged because of tensions between organizational strategies and individual beliefs. At times, agreements between organizations constrained individuals to act fully in accordance with their beliefs, for example, by prohibiting contacts with organizations not included in the agreement. Consider for instance how Vogelesang at TU Delft experienced the consolidated network around the cooperation between Airbus and Stork Fokker:

Eventually, [Stork] Fokker started to collaborate with Airbus. And those two told the Americans that they were not getting any information. They would not get a sublicense. So that's the situation. For me, as a university [researcher], that was very annoying, because we obviously were used to the freedom to experiment in the lab.

Thus, network consolidation aligned and solidified ties at both levels yet, at the same time, acted as a constraint for some to fully enact personal beliefs or pursue certain technological or network development directions. Thus, in the perspective of technology-oriented individuals, consolidation resulted in overembeddedness (cf. Uzzi 1997)—consolidated structures were experienced as overly constraining. In cases like this, tensions could build up, resulting in attempts to release this tension by establishing new or reconfiguring existing interorganizational arrangements. Important enablers for the sequencing of (repeated) consolidation and reconfiguration were strong interpersonal ties-both beyond and nested in the interorganizational collaboration-of individuals that could shape both levels of network cooperation because 
of their expert status (see Table 3). Thus, the consolidation in the 2002 cooperation between Airbus and Stork Fokker led to a reconfiguration of the network in 2004 with the founding of GTM. Furthermore, Figure 2 shows that such a reconfiguration can result in new consolidation, if strategic fit with the new network direction emerges at the interorganizational level, aligned with shared personal beliefs and enabled by hierarchical or expert power.

The third (3) prevailing sequence describes network contraction from prospecting and consolidation toward dissolution, representing a cul-de-sac in network development. Dissolution episodes were prompted by critical changes in conditions at the organizational level: the fit between strategy and opportunity vanished, or indirect interorganizational ties constrained further collaboration. Such changes were possible because FML collaboration was based on not only technological but also commercial, financial, strategic, and legal concerns. Bucci noted,

The Alcoa Technical Center researchers were excited about these kinds of innovative ideas... as a breakthrough technology that could compete and potentially surpass the promise of composites. However, this did not come without internal conflict as business segments of the company, while supporting a defense against [other companies'] composites, viewed the technology as a departure from its traditional flat rolled product manufacturing comfort zone... as well as a technology that could potentially erode some [of our own] highly profitable sheet and plate business.

Perceptions of strategic fit between organizations changed over time, as a result of "strategic drift" (cf. Johnson 1988) and exogenous changes in markets and technologies (cf. Ahuja 2000, Gulati and Gargiulo 1999). Evaluations of such strategy and opportunity fit were affected by changes in board membership, the initiation and abandonment of aircraft development programs, the rise of composites as a competing material, and moves of competitors and customers. As a result, interorganizational collaboration proved volatile and transient, as evidenced, for example, by Alcoa's changing involvement in FML. Similarly, the involvement of Bombardier in 1996 did not grow into wider network cooperation. On the contrary, for Bombardier, the strategic opportunity to apply Glare gradually disappeared as composites gained ground. Moreover, indirect ties consolidated around Stork Fokker and Airbus prevented further consolidation around Bombardier. Eventually, the collaboration was halted at the corporate level, whereas at the interpersonal level, individuals lacked the hierarchical position and autonomy to continue cooperation, which precluded persistence to occur.

The fourth (4) and last prevailing sequence relates to persistence as a bridge between consolidation and future prospecting, showing network survival and reinvigoration against the tide. Whereas the involvement of organizations was subject to external developments and multiple criteria, the involvement of individuals was relatively stable as relationships and shared beliefs coevolved. Some organizations chose to abandon FML for commercial or strategic reasons, whereas individuals remained committed to FML:

You'll find that technologists will tend to have their allegiance to technology before they have allegiance to business. That's my experience.

(Bill Evancho)

Interorganizational ties were broken in persistence episodes, but individuals used their autonomy and hierarchical or expert power to maintain interpersonal ties in which beliefs about technological developments were shared. These ties helped to create or recreate formalized interorganizational relationships-under the condition that a new fit with the organizational strategy emerged.

\section{Discussion}

This paper provides a unique study of the ongoing interaction between interpersonal and interorganizational networks. Using structuration theory as a lens to understand interorganizational collaboration, our analysis reveals five episode types where (1) changes in interorganizational networks are resisted by individuals to retain or reenact existing structures (persistence), (2) interpersonal networks play a catalytic role later ratified by interorganizational networks (prospecting), (3) interpersonal networks are cultivated within interorganizational networks (consolidation), (4) severed interorganizational ties coincide with severed interpersonal ties (dissolution), and (5) individual actions rooted in interpersonal networks change the network system (reconfiguration). These episode types corroborate and extend prior literature. Prospecting captures the established finding that interpersonal networks enable the development of more formal networks (e.g., Barden and Mitchell 2007, Rosenkopf et al. 2001), consolidation confirms that formal collaborations breed informal networks (Dahl and Pedersen 2004, Gulati 1995a), and dissolution was also observed before (Seabright et al. 1992). The identification of reconfiguration and persistence, characterized by tensions between interpersonal and interorganizational collaboration, adds novelty to the literature, as does our analysis of episode sequences.

Our findings on the interaction of interpersonal and interorganizational networks advance emerging theory on multiple levels of embeddedness (Dacin et al. 1999, Hagedoorn 2006). First, our findings show network embeddedness to be distributed across individuals in organizations (insofar as embeddedness depends on interpersonal relations). Whereas earlier studies have largely focused on personal ties among organizational leaders, we find influential interpersonal contacts among a range of boundary spanners, including researchers and developers, marketers, program managers, midlevel managers, and group leaders (cf. Rosenkopf et al. 2001). 
Because contacts primarily concern individuals, they are not directly available to other organization members or executives. The enabling and constraining effects of these ties do not concern the organization as a whole, nor a single actor within an organization like a CEO, but dispersed parts of it, making embeddedness a distributed resource.

Second, the investigation of the multiple levels involved in network embeddedness revealed incongruence among these levels. Rousseau (1985) argued that theories covering multiple levels should take into account the consequences of partial inclusion in higher-level entities. In our study, interpersonal relations that were not nested within interorganizational relationships contributed significantly to network dynamics. In particular, the persistence and reconfiguration episodes revealed in this study stem from limited inclusion of interpersonal relations in interorganizational relations. The opportunities arising from the shared beliefs and commitment in interpersonal relations may differ from, and even conflict with, those arising from interorganizational-level relations. Interpersonal relationships that are beyond interorganizational relations experience less influence from those interorganizational relations (cf. Rousseau 1985) and are more likely to be a source of change. By acknowledging this incongruence between interorganizational and interpersonal relations, we provide a richer and more nuanced view of the multiple levels of embeddedness.

Third, results show that the multiple levels of embeddedness apply both to relational and structural embeddedness. Existing studies of the role of interpersonal relationships were limited to dyads of organizations (e.g., Barden and Mitchell 2007, Gulati and Sytch 2008, Rosenkopf et al. 2001, Zaheer et al. 1998). We broadened the analysis from the dyad to the network. The relations among organizations and individuals were surrounded by relations with and among other organizations and individuals. These indirect ties were influential in several of the episodes analyzed in our case study. Indirect interpersonal ties helped to establish and change interorganizational ties and supported the persistence of direct interpersonal ties. Similar effects were found at the interorganizational level (cf. Gulati 2007), and we also identified constraining effects of indirect interorganizational ties in dissolution and reconfiguration episodes. The significance of indirect interpersonal ties adds to potential incongruence between levels of embeddedness.

These characteristics of the multiple levels of embeddedness have implications for both short-term and longer-term network development and change processes. Using the "duality of structure" as a sensitizing concept, we investigated sequences of episodes in which structures are both the medium and the outcome of action. The dynamics that follow from the multiple levels of embeddedness support a dialectical understanding of interorganizational collaboration and point at limitations of evolutionary and teleological explanations. Dialec- tical processes are driven by multiple entities pursuing antithetical objectives and may lead to constructive change (Van de Ven and Poole 1995). Earlier dialectical process studies have analyzed tensions between partnering organizations (de Rond and Bouchikhi 2004, Sydow 2004). We add a "vertical" dimension to this "horizontal" dimension: just as the interpersonal network is partly controlled by organizations, the interorganizational network is also partly controlled by interpersonal networking. Tensions are introduced in a network system when interpersonal relations are distributed and not fully nested in interorganizational relations, and these tensions can lead to network actions that resolve tensions or create new ones.

Analysis of sequences among episodes revealed convergent and divergent dialectics in the long-term interactions of the interorganizational or interpersonal network. The two levels of the network system were found to be mutually reinforcing when individual relations helped to create and exploit relations between organizations, whereas organization-level arrangements supported the development of interpersonal ties. However, interpersonal ties did not only lubricate interorganizational-level collaboration; they also enabled divergent dynamics. Consolidation was also followed by reconfiguration, when interorganizational agreements constrained individuals who in turn used their interpersonal ties to change and renew the network. Persistence bridged organization-level collaborations when beliefs shared in interpersonal relations proved to be more stable than organizational commitments.

We found two factors that increased the significance of individual-level relations for interorganizational network dynamics: (1) The divergence of individual beliefs and organization-level strategic considerations spur persistence and reconfiguration (cf. Burgelman and Grove 1996). In our study, individual-level collaboration was often based on a shared drive to advance FML, whereas decision making at the organizational level included commercial, strategic, and legal motives as well. The inclusion of multiple motives resulted in agreements that also constrained individuals to act on shared beliefs and that were more susceptible to exogenous changes. (2) The positions of individuals influence the degree to which they are able to deploy interpersonal relations. A degree of autonomy helps to sustain interpersonal contacts that are not nested in interorganizational relations, a higher hierarchical position helps to transform interpersonal contacts into interorganizational agreements, and expert power helps to use interpersonal networks to reconfigure and shake up a network system.

Simultaneously, our findings point at limits of evolutionary and teleological explanations of network dynamics. Previous studies on embeddedness found evolutionary, path-dependent network development processes, exemplified by the tendency to replicate existing ties (Gulati 1995b, Gulati and Gargiulo 1999). The 
dominant explanation for tie replication is that collaboration creates trust between organizations, which increases the likelihood of future collaboration. Indeed, our findings show how the replication of ties may occur through consolidation and prospecting, stressing the dependence on interpersonal networks as the locus of trust and the source of renewal of the interorganizational relationship. This mechanism of path dependence, however, does not explain all network dynamics resulting from embeddedness. Because interpersonal relations may be dispersed over organizations and may be more than a trivial reproduction of interorganizational relations, existing relations allow multiple paths to be explored. The multiple direct and indirect ties at both levels that may be enacted create an array of potential paths for network change. The structuration of network relations in such a layered system does not only amount to the reproduction of relations but also opens up alternative opportunities, including significant departures from existing paths.

Network dynamics in this study also point to limitations of intentional network design and orchestration, as stressed in teleological perspectives (e.g., Dhanaraj and Parkhe 2006, Doz et al. 2000). Our study did show instances of proactive network construction, for example, in the 1991 consolidation episode centering on SLC. The distributed nature of embeddedness, though, makes it more difficult to purposefully use embeddedness as a strategic organizational resource. The more the beliefs and interests shared at the individual level differ from organizational strategies, and the more individuals have the autonomy and the position to use their relations, the more the network system will defy orchestration.

Paradoxically, the diverging dialectics that defy orchestration and path dependence were essential for network continuity and reinvigoration of collaboration in our study. Organizations entered but also withdrew from the network for strategic reasons, and these dynamics threatened the survival of the network system. At the same time, the interpersonal network proved fairly stable, and this stability enabled continued collaboration and eventual reemergence of interorganizational relations. Network reconfiguration also opened up new developments, as when the founding of GTM created opportunities not feasible within the structure in which Airbus and Stork Fokker were central. Thus, we extend Gulati and Puranam's (2009) argument that inconsistencies between formal and informal organization are valuable for renewal from the intraorganizational to the interorganizational domain.

Finally, interpersonal relations may aggravate as well as reduce negative consequences of embeddedness. A key mechanism of embeddedness in our case study was the development of shared beliefs and mutual understanding among individuals in the network. Yet reinforcing effects of relations and shared understanding might also turn into a barrier to renewal. The commitments and "blindness" associated with existing relationships make it more difficult to enter into new relationships (Capaldo 2007, Gargiulo and Benassi 2000, Uzzi 1997). Although interpersonal relationships may be a source of such overembeddedness, they can also be used to overcome that dark side. Episodes of prospecting and reconfiguration can open up new possibilities for collaboration, thus reducing the threat of becoming locked into structural rigidities.

These theoretical advancements notwithstanding, there are several limitations to this study. First, the findings are based on a retrospective study, which limits the accuracy and completeness of data, in particular, on interpersonal relations from the early phases of the case history. A real-time network development study instead of a retrospective study could uncover additional insights in the interaction between interpersonal and interorganizational networks because such a study can gather information from all participants and all possible relations over time. Second, our findings are based on a single case in a specific context. The five episode types discerned here may be typical for multipartner alliances and networks in an innovation context, as the importance of interpersonal networks in R\&D consortia is well established, and networks around technology ventures tend be based on embedded relations instead of arms-length relations (e.g., Doz et al. 2000, Liebeskind et al. 1996, Hite and Hesterly 2001). Yet similar interactions between interpersonal and interorganizational networks might also be found in other contexts that center on relatively autonomous professionals, who have to balance loyalty toward their organization with loyalties toward the community of peers and loyalty toward a shared idea, vision, or passion. Examples could be the network system of medical specialists or that of politicians and political parties. Furthermore, as the network around FML has showed more expansion than contraction so far, case studies of networks exhibiting more contraction may uncover variants of the episode types we describe. Future research may also discriminate between different types of interorganizational relations, such as alliances, supply relationships, or licensing, because these types are associated with different levels of embeddedness at the interorganizational level (Gulati 1995a). Finally, we have limited our analysis to two levels: interpersonal networks and interorganizational networks. One way to extend this research is to include other levels in the analysis, such as the institutional environment (cf. Marchington and Vincent 2004) and organizational interunit relations (cf. Brass et al. 2004).

\section{Conclusion}

This study has explored a new direction for research on interorganizational networks, by investigating dynamics resulting from multiple levels of embeddedness in a retrospective longitudinal case study. By going back 30 years in history, we could analyze network dynamics associated with multiple failed and successful attempts 
to apply FML in the primary structure of aircraft. This long period of time enabled us to link conditions for agency in one episode back to structures created in episodes as far as 10 years back. In the analysis of episodes, we identified five types of interaction between interpersonal and interorganizational networks, conditions for these episode types, and sequences among them. Our findings indicate that embeddedness in relations and networks is no centrally available resource, but it is partly distributed over individuals in organizations and not congruent across levels. As a result, the types of interaction entail both converging and diverging dialectics between interpersonal and interorganizational networks, which contributes to the emergent nature of network development. The dialectical structuration of interorganizational and interpersonal networks affects the path-dependent, evolutionary processes associated with embeddedness and limits the teleological shaping of networks. We conclude that full understanding of network development requires the combination of these multiple theoretical mechanisms (cf. de Rond 2003). Future research is needed to explore the balance and interplay of these mechanisms in other network contexts.

\section{Acknowledgments}

The authors thank senior editor Tina Dacin and three anonymous reviewers for their constructive feedback and guidance throughout the review process. They are grateful to Mariann Jelinek, Arjan van Weele, Myriam Cloodt, Tony Hak, and seminar participants at Tilburg University, the Rotterdam School of Management, and the University of Reading for comments and input during the development of this paper. Finally, they thank the interviewees for generously giving their time. An earlier version of this paper was presented at the Academy of Management Conference 2007. All errors are the responsibility of the authors.

\section{References}

Ahuja, G. 2000. The duality of collaboration: Inducements and opportunities in the formation of interfirm linkages. Strategic Management J. 21(3) 317-343.

Aiken, M., J. Hage. 1968. Organizational interdependence and intraorganizational structure. Amer. Sociol. Rev. 33(6) 912-930.

Ariño, A., J. de la Torre. 1998. Learning from failure: Towards an evolutionary model of collaborative ventures. Organ. Sci. 9(3) 306-325.

Barden, J. Q., W. Mitchell. 2007. Disentangling the influences of leaders' relational embeddedness on interorganizational exchange. Acad. Management J. 50(6) 1440-1461.

Bell, J., B. den Ouden, G. W. Ziggers. 2006. Dynamics of cooperation: At the brink of irrelevance. J. Management Stud. 43(7) 1607-1619.

Blumer, H. 1954. What is wrong with social theory? Amer. Sociol. Rev. 19(1) 3-10.

Bouty, I. 2000. Interpersonal and interaction influences on informal resource exchanges between R\&D researchers across organizational boundaries. Acad. Management J. 43(1) 50-65.

Brass, D. J., J. Galaskiewicz, H. R. Greve, W. Tsai. 2004. Taking stock of networks and organizations: A multilevel perspective. Acad. Management J. 47(6) 795-817.
Brown, J. S., P. Duguid. 2001. Knowledge and organization: A socialpractice perspective. Organ. Sci. 12(2) 198-213.

Browning, L. D., J. M. Beyer, J. C. Shetler. 1995. Building cooperation in a competitive industry: SEMATECH and the semicomputer industry. Acad. Management J. 38(1) 113-151.

Burgelman, R. A., A. S. Grove. 1996. Strategic dissonance. Calif. Management Rev. 38(2) 8-28.

Capaldo, A. 2007. Network structure and innovation: The leveraging of a dual network as a distinctive relational capability. Strategic Management J. 28(6) 585-608.

Chung, S. A., H. Singh, K. Lee. 2000. Complementarity, status similarity and social capital as drivers of alliance formation. Strategic Management J. 21(1) 1-22.

Dacin, M. T., M. J. Ventresca, B. D. Beal. 1999. The embeddedness of organizations: Dialogue and directions. J. Management 25(3) $317-356$.

Dahl, M. S., C. Ø. R. Pedersen. 2004. Knowledge flows through informal contacts in industrial clusters: Myth or reality? Res. Policy 33(10) 1673-1686.

Das, T. K., B.-S. Teng. 2000. Instabilities of strategic alliances: An internal tensions perspective. Organ. Sci. 11(1) 77-101.

D'Aunno, T. A., H. S. Zuckerman. 1987. A life-cycle model of organizational federations: The case of hospitals. Acad. Management Rev. 12(3) 534-545.

de Rond, M. 2003. Strategic Alliances as Social Facts: Business, Biotechnology, and Intellectual History. Cambridge University Press, Cambridge, UK.

de Rond, M., H. Bouchikhi. 2004. On the dialectics of strategic alliances. Organ. Sci. 15(1) 56-69.

Dhanaraj, C., A. Parkhe. 2006. Orchestrating innovation networks. Acad. Management Rev. 31(3) 659-669.

Doz, Y. L. 1996. The evolution of cooperation in strategic alliances: Initial conditions or learning processes? Strategic Management J. 17(S1) 55-83.

Doz, Y. L., P. M. Olk, P. S. Ring. 2000. Formation processes of R\&D consortia: Which path to take? Where does it lead? Strategic Management J. 21(3) 239-266.

Eisenhardt, K. M., C. B. Schoonhoven. 1996. Resource-based view of strategic alliance formation: Strategic and social effects in entrepreneurial firms. Organ. Sci. 7(2) 136-150.

Fredell, R. 1994. Damage tolerant repair techniques for pressurized aircraft fuselages. Unpublished doctoral dissertation, Delft University of Technology, Delft, The Netherlands.

Fredell, R. S., J. W. Gunnink, R. J. Bucci, J. Hinrichsen. 2007. "Carefree" hybrid wing structures for aging USAF transports. Paper, First International Conference on Damage Tolerance of Aircraft Structures, September 25-28, Delft University of Technology, Delft, The Netherlands.

Gargiulo, M., M. Benassi. 2000. Trapped in your own net? Network cohesion, structural holes, and the adaptation of social capital. Organ. Sci. 11(2) 183-196.

Giddens, A. 1976. New Rules of Sociological Method. Basic Books, New York.

Giddens, A. 1984. The Constitution of Society. Polity Press, Cambridge, UK.

Golden, B. R. 1992. The past is the past-Or is it? The use of retrospective accounts as indicators of past strategy. Acad. Management J. 35(4) 848-860.

Granovetter, M. 1985. Economic action and social structure: The problem of embeddedness. Amer. J. Sociol. 91(3) 481-510.

Granovetter, M. 1992. Problems of explanation in economic sociology. N. Nohria, R. G. Eccles, eds. Networks and Organizations: 
Strucutre, Form and Action. Harvard Business School Press, Boston, 25-56.

Gregory, M. A., G. H. J. J. Roebroeks. 1991. Fiber-metal laminates: A solution to weight, strength, and fatigue problems. Paper, 30th Annual Conference of Metallurgists, August 18-21, Metallurgical Society of CIM, Canadian Institute of Mining, Metallurgy and Petroleum, Ottowa, ON, Canada.

Gulati, R. 1995a. Does familiarity breed trust? The implications of repeated ties for contractual choices in alliances. Acad. Management J. 38(1) 85-112.

Gulati, R. 1995b. Social structure and alliance formation patterns: A longitudinal analysis. Admin. Sci. Quart. 40(4) 619-652.

Gulati, R. 1998. Alliances and networks. Strategic Management J. 19(4) 293-317.

Gulati, R. 2007. Managing Network Resources: Alliances, Affiliations and Other Relational Assets. Oxford University Press, Oxford, UK.

Gulati, R., M. Gargiulo. 1999. Where do interorganizational networks come from? Amer. J. Sociol. 104(5) 1439-1493.

Gulati, R., P. Puranam. 2009. Renewal through reorganization: The value of inconsistencies between formal and informal organization. Organ. Sci. 20(2) 422-440.

Gulati, R., M. Sytch. 2008. Does familiarity breed trust? Revisiting the antecedents of trust. Managerial Decision Econom. 29(2-3) 165-190.

Gulati, R., J. D. Westphal. 1999. Cooperative or controlling? The effects of CEO-board relations and the content of interlocks on the formation of joint ventures. Admin. Sci. Quart. 44(3) 473-506.

Hagedoorn, J. 2006. Understanding the cross-level embeddedness of interfirm partnership formation. Acad. Management Rev. 31(3) 670-680.

Halinen, A., A. Salmi, V. Havila. 1999. From dyadic change to changing business networks: An analytical framework. J. Management Stud. 36(6) 779-794.

Hite, J. M., W. S. Hesterly. 2001. The evolution of firm networks: From emergence to early growth of the firm. Strategic Management J. 22(3) 275-286.

Huber, G. P., D. J. Power. 1985. Retrospective reports of strategiclevel managers: Guidelines for increasing their accuracy. Strategic Management J. 6(2) 171-180.

Hung, H. 2006. Formation and survival of new ventures: A path from interpersonal to interorganizational networks. Internat. Small Bus. J. 24(4) 359-378.

Jap, S. D., E. Anderson. 2007. Testing a life-cycle theory of cooperative interorganizational relationships: Movement across stages and performance. Management Sci. 53(2) 260-275.

Jick, T. D. 1979. Mixing qualitative and quantitative methods: Triangulation in action. Admin. Sci. Quart. 24(4) 602-611.

Johnson, G. 1988. Rethinking incrementalism. Strategic Management J. 9(1) 75-91.

Jones, C., W. S. Hesterly, S. P. Borgatti. 1997. A general theory of network governance: Exchange conditions and social mechanisms. Acad. Management Rev. 22(4) 911-945.

Katz, J. S., B. R. Martin. 1997. What is research collaboration? Res. Policy 26(1) 1-18.

Kim, J. W., M. C. Higgins. 2007. Where do alliances come from? The effects of upper echelons on alliance formation. Res. Policy 36(4) 499-514.

Klein, K. J., S. L. Palmer, A. B. Conn. 2000. Interorganizational relationships: A multilevel perspective. K. J. Klein, S. W. J. Kozlowski, eds. Multilevel Theory, Research and Methods in Organizations. Jossey-Bass, San Francisco, 267-307.
Koza, M. P., A. Y. Lewin. 1999. The coevolution of network alliances: A longitudinal analysis of an international professional service network. Organ. Sci. 10(5) 638-653.

Krackhardt, D. 1990. Assessing the political landscape: Structure, cognition, and power in organizations. Admin. Sci. Quart. 35(2) 342-369.

Kreiner, K., M. Schultz. 1993. Informal collaboration in R\&D: The formation of networks across organizations. Organ. Stud. 14(2) 189-209.

Kumar, R., K. O. Nti. 1998. Differential learning and interaction in alliance dynamics: A process and outcome discrepancy model. Organ. Sci. 9(3) 356-367.

Langley, A. 1999. Strategies for theorizing from process data. Acad. Management Rev. 24(4) 691-710.

Laudel, G. 2002. What do we measure by co-authorships? Res. Evaluation 11(1) 3-15.

Laumann, E. O., J. Galaskiewicz, P. V. Marsden. 1978. Community structure as interorganizational linkages. Annual Rev. Sociol. 4 $455-484$.

Lee, T. W. 1999. Using Qualitative Methods in Organizational Research. Sage, Thousand Oaks, CA.

Leonard-Barton, D. 1992. Core capabilities and core rigidities: A paradox in managing product development. Strategic Management J. 13(S1) 111-125.

Li, S. X., W. B. Berta. 2002. The ties that bind: Strategic actions and status structure in the US investment banking industry. Organ. Stud. 23(3) 339-368.

Liebeskind, J. P., A. L. Oliver, L. Zucker, M. Brewer. 1996. Social networks, learning, and flexibility: Sourcing scientific knowledge in new biotechnology firms. Organ. Sci. 7(4) 428-443.

Lorenzoni, G., A. Lipparini. 1999. The leveraging of interfirm relationships as a distinctive organizational capability: A longitudinal study. Strategic Management J. 20(4) 317-338.

Marchington, M., S. Vincent. 2004. Analysing the influence of institutional, organizational and interpersonal forces in shaping interorganizational relations. J. Management Stud. 41(6) 1029-1056.

McGuire, J. B. 1988. A dialectical analysis of interorganizational networks. J. Management 14(1) 109-124.

Meyer, M., S. Bhattacharya. 2004. Commonalities and differences between scholarly and technological collaboration. Scientometrics 61(3) 443-456.

Miller, C. C., L. B. Cardinal, W. H. Glick. 1997. Retrospective reports in organizational research: A reexamination of recent evidence. Acad. Management J. 40(1) 189-204.

Mueller, R. P. G. 1995. An experimental and analytical investigation on the fatigue behaviour of fuselage riveted lap joints. Unpublished doctoral dissertation, Delft University of Technology, Delft, The Netherlands.

Oliver, A. L., J. Liebeskind. 1998. Three levels of networking for sourcing intellectual capital in biotechnology: Implications for studying interorganizational networks. Internat. Stud. Management Organ. 27(4) 76-103.

Olk, P., C. Young. 1997. Why members stay in or leave an R\&D consortium: Performance and conditions of membership as determinants of continuity. Strategic Management J. 18(11) 855-877.

Pettigrew, A. M. 1990. Longitudinal field research on change: Theory and practice. Organ. Sci. 1(3) 267-292.

Powell, W. W., K. Koput, L. Smith-Doerr. 1996. Interorganizational collaboration and the locus of innovation: Networks of learning in biotechnology. Admin. Sci. Quart. 41(1) 116-145. 
Powell, W. W., D. R. White, K. W. Koput, J. Owen-Smith. 2005. Networks dynamics and field evolution: The growth of interorganizational collaboration in the life sciences. Amer. J. Sociol. 110(4) 1132-1205.

Pozzebon, M., A. Pinsonneault. 2005. Challenges in conducting empirical work using structuration theory: Learning from IT research. Organ. Stud. 26(9) 1353-1376.

Ring, P. S., A. H. Van de Ven. 1994. Developmental processes of cooperative interorganizational relationships. Acad. Management Rev. 19(1) 90-118.

Rosenkopf, L., A. Metiu, V. P. George. 2001. From the bottom up? Technical committee activity and alliance formation. Admin. Sci. Quart. 46(4) 748-772.

Rousseau, D. M. 1985. Issues of level in organizational research: Multi-level and cross-level perspectives. L. L. Cummings, B. M. Staw, eds. Research in Organizational Behavior, Vol. 7. JAI Press, Greenwich, CT, 1-37.

Schrader, S. 1991. Informal technology transfer between firms: Cooperation through information trading. Res. Policy 20(2) 153-170.

Schwenk, C. R. 1985. The use of participant recollection in the modelling of organizational decision processes. Acad. Management Rev. 10(3) 496-503.

Seabright, M. A., D. A. Levinthal, M. Fichman. 1992. Role of individual attachments in the dissolution of interorganizational relationships. Acad. Management J. 35(1) 122-160.

Siggelkow, N. 2007. Persuasion with case studies. Acad. Management J. 50(1) 20-24.

Strauss, A. L. 1987. Qualitative Analysis for Social Scientists. Cambridge University Press, Cambridge, UK.

Sydow, J. 2004. Network development by means of network evaluation? Explorative insights from a case in the financial services industry. Human Relations 57(2) 201-220.

Sydow, J., A. Windeler. 1998. Organizing and evaluating interfirm networks: A structurationist perspective on network processes and effectiveness. Organ. Sci. 9(3) 265-284.

Sydow, J., A. Windeler. 2003. Knowledge, trust, and control: Managing tensions and contradictions in a regional network of service firms. Internat. Stud. Management Organ. 33(2) 69-99.

Tichy, N. M., M. L. Tushman, C. Fombrun. 1979. Social network analysis for organizations. Acad. Management Rev. 4(4) 507-519.

Tsai, W. 2000. Social capital, strategic relatedness and the formation of intra-organizational linkages. Strategic Management J. 21(9) 925-939.

Uzzi, B. 1997. Social structure and competition in interfirm networks: The paradox of embeddedness. Admin. Sci. Quart. 42(1) $35-67$.

Van de Ven, A. H. 1976. On the nature, formation, and maintenance of relations among organizations. Acad. Management Rev. 1(4) $24-36$.
Van de Ven, A. H., M. S. Poole. 1995. Explaining development and change in organizations. Acad. Management Rev. 20(3) $510-540$.

Vermeeren, C., ed. 2002. Around Glare: A New Aircraft Material in Context. Kluwer Academic Publishers, Dordrecht, The Netherlands.

Vlot, A. 2001. Glare: History of the Development of a New Aircraft Material. Kluwer Academic Publishers, Dordrecht, The Netherlands.

Vlot, A., J. W. Gunnink, eds. 2001. Fiber Metal Laminates: An Introduction. Kluwer Academic Publishers, Dordrecht, The Netherlands.

Vogelesang, B. 2003. Fibre metal laminates: The development of a new family of hybrid materials. Presentation, 19th Plantema Memorial Lecture, ICAF Symposium, May 5-9, Lucern, Switzerland.

von Hippel, E. 1987. Cooperation between rivals: Informal know-how trading. Res. Policy 16(6) 291-302.

Walker, G., B. Kogut, W. Shan. 1997. Social capital, structural holes and the formation of an industry network. Organ. Sci. 8(2) 109-125.

Westphal, J. D., S. Boivie, D. H. M. Chng. 2006. The strategic impetus for social network ties: Reconstituting broken CEO friendship ties. Strategic Management J. 27(5) 425-445.

Wu, H. F., L. L. Wu, W. J. Slagter, J. L. Verolme. 1994. Use of rule of mixtures and metal volume fraction for mechanical property predictions of fiber-reinforced aluminum laminates. J. Materials Sci. 29(17) 4583-4591.

Yin, R. K. 2003. Case Study Research: Design and Methods, 3rd ed. Sage, Thousand Oaks, CA.

Zaheer, A., B. McEvily, V. Perrone. 1998. Does trust matter? Exploring the effects of interorganizational and interpersonal trust on performance. Organ. Sci. 9(2) 141-159.

Zeitz, G. 1980. Interorganizational dialectics. Admin. Sci. Quart. 25(1) $72-88$.

Hans Berends is an assistant professor in the Innovation, Technology Entrepreneurship and Marketing Group at the Eindhoven University of Technology. His research interests concern process dynamics of innovation and organizational learning.

Elco van Burg is an assistant professor in the Innovation, Technology Entrepreneurship and Marketing Group at the Eindhoven University of Technology. He studies entrepreneurship and innovation processes.

Erik M. van Raaij is an assistant professor of purchasing and supply management at the Rotterdam School of Management, Erasmus University. His current research focuses on strategic sourcing and buyer-supplier relationships. 